\title{
The Effect of Normative Social Influence and Cultural Diversity on Group Interactions
}

\author{
Zixiu Guo \\ The University Of New \\ South Wales, \\ Australia \\ z.guo@unsw.edu.au
}

\author{
Tim Turner \\ Australian Defence Force \\ Academy, \\ The University Of New South \\ Wales, Australia \\ Tim.turner@adfa.edu.au
}

\author{
Felix Tan \\ Auckland University of \\ Technology, \\ New Zealand \\ Felix.tan@aut.ac.nz
}

\begin{abstract}
Motivated by concerns regarding the impact of cultural diversity on group interaction processes and a desire to extend the Social Influence Model of Technology Use, this paper discusses the impact of normative social influence on enhancing group media use and group decision making performance over time in different cultural group compositions. This paper proposes that the strength of attraction to the group influences the similarity in media perception and use of group members. The similarity of group media perception and use is proposed to influence group performance. Concurrently, group cohesion, similarity of media perception and use, and group performance are positively correlated over time. Since culture affects individuals' values, beliefs and behavior, this paper proposes that the degree of similarity in media perception and media use may differ when group composition varies by culture. Several propositions for empirical examination are highlighted. Finally, the paper concludes with a discussion of the importance and implications of understanding cultural diversity and social influence on technology use and group performance.
\end{abstract}

\section{Introduction}

Grounded in the belief that social interaction in the workplace shapes the creation of shared meanings and that these shared meanings provide an important basis for shared patterns of media selection, Fulk and her colleagues [16, 17] developed "The Social Influence Model of Technology Use" to explain the accumulating body of anomalous findings in media richness theory, especially for new communication media. The model focuses on the role of social information to explain media use. It posits that social forces such as workgroup norms and co-workers' and supervisors' attitudes and behavior will influence individual perceptions and choices of new media. The net effect is to produce "a similar pattern of media attitude and use behavior within groups, even across tasks with different communication requirements," and "different patterns of media usage across groups" [17, p542-543].

While the social influence model of technology use has found empirical support with perceptions and use of email being influenced by variables such as coworkers' perceptions of and use of the medium [14, $26,40,50]$, there are some issues arising from the model.

Firstly, few of the empirical studies that tested the social influence model of technology use have explicitly examined the similarity of media perception and use within groups and the differences across groups. Little is known about how such patterns develop within and across groups. According to social information processing theory, there are actually two different mechanisms, informational social influence and normative social influence, accounting for the effects of context or the environment on individual behavior [30,33]. This distinction is important since previous investigations of the social influence on media choice have concentrated almost exclusively on informational social influence and ignored the impacts of normative social influence. Fulk [14] and Yoo et al. [52] argue that the members' attraction to the group, called group cohesion, influences workgroup technology attitudes, social presence, task participation, and group consensus. But this premise, as articulated in relation to normative social influence, has not been discussed explicitly, especially as a mechanism to promote similar media attitudes and use 
within groups. This creates a void in the literature. There is, therefore, a need to examine how normative social influence plays a role on communication media use.

Secondly, although numerous studies have examined the social influence model in a mediated communication system, most of them stop when media choices are made [15]. What are the effects of media choice? What is the consequence of media choice to organizational performance? In terms of the social influence model of technology use, nothing is known about the effect of the similarity of media perception and use on group performance. ComputerMediated Communications (CMCs) have played a distinctly social, interpersonal role in organizations. Numerous theories and frameworks have been introduced to describe how CMC improves various aspects of group performance [e.g. 1, 2, 4, 52]. Thus, taking a step forward, this paper aims to examine how the impact of normative social influence on media use affects group performance.

Thirdly, most small group CMC studies employ a one-shot laboratory experiment methodology with ad hoc groups, completely ignoring the effects of time on group social interaction and performance in a mediated communication environment. However, a number of studies have demonstrated that the nature of a group's social interaction process and performance changes over time [5, 47]. Thus, it is necessary to study group social interaction and performance over multiple time periods to reveal the true nature or the relationships between these constructs.

Finally, this paper also attempts to shed light on the impact of cultural diversity on this extended model. As Watson et al [48] note, "cross-cultural studies of computer-mediated technology are highly relevant to a post-industrial society in which managerial teams, often composed of individuals from different national cultures, will make extensive use of information technology to support group decision making." Despite recognizing the potential importance of national culture to the process and performance of groups using computer-mediated technology [50], very few studies have used this variable. Very little empirical research or systematic conceptual work has directly addressed the important and timely phenomenon of cultural heterogeneity in group interaction and decision making. In today's major organizations, task groups consisting of multiple nationalities abound, and the clear trend is towards even more of them in the future. Thus, it is time to take to action. Cox et al. say [6] that "unless organizations start managing diversity, they will find themselves at a competitive disadvantage." Since social influence is related to individualism/collectivism, a cultural dimension that distinguishes people from different cultures in terms of their value concerning the relation of an individual to his or her collectivity in society, this paper presents a research model to compare groups that are culturally homogeneous and heterogeneous in terms of individualism and collectivism.

The primary purpose of paper is to extend the Social Influence Model of Technology Use by examining the impact of normative social influence and cultural diversity on technology use and group performance over time. Normative social influence, media perception and use similarity, and cultural traits are indispensable when considering fundamental group decision making performance in computermediated communication environment. The next section illustrates our research framework. Then we discuss relevant theoretical perspectives and lay out our research propositions. The paper concludes with a discussion of the importance and implications of understanding cultural diversity and social influence on technology use and group performance.

\section{Research Framework}

This paper seeks to explore the impact of normative social influence on media use and group performance over time in various cultural group compositions. To achieve this, an input-processoutput model of group interaction (see Figure 1) has been adopted as the organizing framework. The two independent variables of interest are (a) group normative social influence, and (b) different cultural group composition. The research model explicitly incorporated time into the group's interaction process. Examining social interaction longitudinally will reveal whether, with the passage of time, as group members interact more intensively and become more familiar with the medium and with each other, their perceptions about the media change and the way they communicate with each other becomes more similar. Ultimately, such interaction processes will have an impact on group performance.

There are four theoretical perspectives relevant to the above framework. The first one focuses on the social influence process on individuals' attitudes, perceptions, and behaviors. The second approach is about national culture. Since each culture has a unique way of doing business and a unique set of values to guide human behavior [43], national culture strongly affects individual behavior, including group interaction, media use and group decision making 
[see 20, for review]. The third one extends the social impact of group norms on individual behavior to group performance. The fourth approach assumes that group work in organizations typically occurs over time and requires sustained interaction [4]. Indeed, over time and with sufficient exposure to the experiences of others, people develop shared understandings about acceptable behavior, which increases their comfort [26]. The discussion below develops these perspectives further.

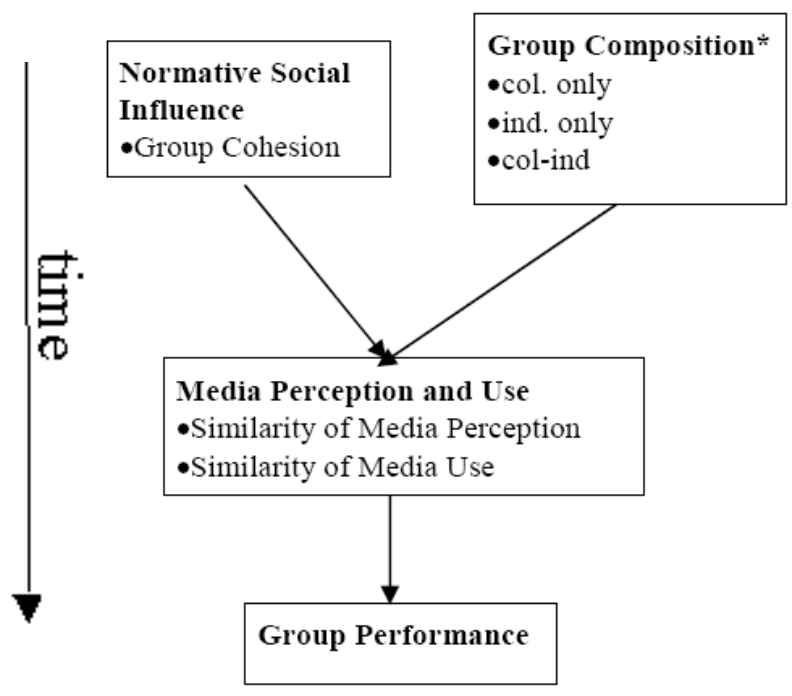

*col only: cultural homogeneous group with collectivistic members only

ind only: cultural homogeneous group with individualistic members only

col-ind: cultural heterogeneous group with collectivistic and individualistic members

Figure 1: Research Model

\section{Theoretical Foundation and Proposition Development}

\subsection{The Impact of Normative Social Influence on Group Members' Media Perception and Use}

There has long been considerable interest in how attitudes, perceptions, and behaviors are affected by various sources of influence that are present in the social environment. Among these modes, two alternative influence modes have been receiving the most attention [8]. The first, normative social influence is based on the desire to conform to the expectations of others. The second, informational social influence is based on the acceptance of information from others as evidence about reality.

The former effect proceeds from a mechanism of social exchange, in which behavior complies with group norms and role expectations with the acceptance of members. The latter effect posits a mechanism of informational influence through uncertainty reduction, in which ambiguity is resolved through reliance on shared judgment and perceptions of salient others [31].

As Deutsch \& Gerard [8] noted, conceptually one can distinguish between normative and informational social influence. The former is based on the pressure or sanctions applied by group members to produce conformity in terms of attitude and behavior. By conformity, it means the change in behavior or beliefs toward a group as a result of real or imagined group pressure. A group is typically recognized through more dense communication within the group than across its boundaries, and a similarity in orientation that distinguishes the group from other social actors in its environment [33]. An individual complies with group norms, and in turn, he or she achieves membership and the social support that such membership affords, as well as goal attainment that can occur only through group actions or group membership. So, normative social influence is also called "group-central" influence, referring to the necessity of convergence towards identical opinions. This is determined by the relations between individuals, not by the properties of the object. The evidence for the impact of normative social influence on individual attitudes and behavior is substantial, ranging from the early study of Festinger et al [12, 13] and Kaplan \& Miller [25] to more recent empirical tests in CMC systems [26, 27, 35, 44].

The impact of normative social influence on perceptions and behavior at work is potentially of great importance for understanding the social constitution of reality. There is every reason to believe that similar processes might be developed in communication behavior within the workplace [17]. Because normative social influence will affect individual beliefs about the nature of jobs and work, about what attitudes are appropriate, and indeed, about how people ought to behave [33], we would expect that media perceptions and use would be constrained by each individual's existing sociallyconstructed "how to's" for interaction with other individuals in the group. Within workgroups, there may emerge a consensus about what are the important features of the work environment regarding media use; in this manner, group members may act to make 
salient certain aspects of media use and downplay others [31]. This may lead to media being perceived and preferred similarly within groups and differently across groups. Further, Postmes et al [35] found that such group norms would influence communication within groups, but not people outside the groups. Thus, in addition to the effects of informational social influence on group members' media perception and use, groups may also develop a normative framework for interpreting and responding to facets of the work environment resulting in a stable social construction of reality that may vary across work groups faced with objectively similar circumstances [31]. Conformity to group norms may lead to similar media perceptions and use within groups and different perceptions and use across groups.

Normative social influence refers to the pressure on individuals to conform to group norms that are implicit or explicit in the choice preference of group members. One index of this conformity pressure may be group cohesion [31]. Group cohesion is defined as "members' attraction to the group" [24, p.30]. It is generally associated with normative pressure to conform, and hence with a drive for consensus and unanimity that implies intolerance toward dissent and intellectual independence of group members [8]. It is often described as resultant forces that are acting on the members to stay in a group [11]. In Social Information Processing terms [38], this pressure for conformity may reduce the variance in members' views and result in greater consistency of attitudes and behaviors. Hence, group cohesion is used as the manifest of normative social influence.

Researchers have frequently considered group cohesion to be an important component of group process and performance [19]. Festinger et al [13] found that highly cohesive groups exerted more pressure on members towards compliance with group norms than did less cohesive groups. Fulk [14] found that the social influences of a workgroup are stronger predictors for individuals with high attraction to their workgroups. Yoo et al. [52] found that group cohesion has a significantly greater influence on social presence and task participation than media condition. We argue that the desirability to maintain their membership in the group calls attention to the potential willingness of the individual to respond to group communication norms, which would lead to similar media perception and use within groups. Such similarity can be strengthened by cohesion that serves to attract group members. Accordingly,

\section{Proposition 1a: A higher degree of group cohesion will increase the similarity of media perception by the group members.}

Proposition 1b: A higher degree of group cohesion will increase the similarity of media use by the group members.

\subsection{The Impact of Normative Social Influence Moderated by National Culture}

However, those associations proposed in propositions $1 \mathrm{a}$ and $1 \mathrm{~b}$ might be moderated by national culture. Culture is the collective programming of the mind that distinguishes the members of one group or category of people from another [22]. Since each culture has unique values to guide human behavior [45], national culture strongly affects management practices, including group interaction and communication [for review, see 20]. The social influence on media choice may differ across cultures [50]. This issue becomes more notable with the globalization of the world market and multinationalism. A cross-cultural study is needed to investigate whether culture will be a critical factor moderating the impact of normative social influence on group interaction.

Individualism/collectivism (I/C), the most important dimension of cross-cultural psychology to date $[42,45]$, has been well researched both in group interaction and communication literature, as well as in other disciplines $[10,18,21,23,37,41,45]$ Individualism stands for a preference for a looselyknit social framework in society wherein individuals are supposed to take care of themselves and their immediate families only. Its opposite, collectivism, represents a preference for a tightly-knit social framework in which individuals can expect their relatives, clan, or other in-group to look after them in exchange for unquestioning loyalty. In an individualistic culture, people tend to see themselves as "I" and strive for self-actualization. They base their self-understanding on their own actions and they are self-oriented and self-centered. They are more likely to follow personal desires [51] that are usually taken independently of what others think [9]. In contrast, people characterized with collectivistic culture, will tend to see themselves as part of "we" and strive for group interest. They are integrated into strong cohesive groups [3] so that they base their selfunderstanding on the reactions of others around them [9]. They are able to protect their social selves and function as an integral part of the social network. Social and structure harmony is created and preserved 
by complex networks. These in turn are sustained by status hierarchies, loyalty to people, and norms of conformance, mutual obligation and reciprocity [28].

The I/C dimension has been used to explain why groups in some countries were more willing to adhere to group norms than groups in other countries [9]. It was also been used in some CMC studies [e.g. 44, 48] to account for the different behaviors during group decision making in both cultures. Since conformity to group norms is the major form of normative social influence on individual's perception and behavior change during group interaction, the $\mathrm{I} / \mathrm{C}$ dimension is a pertinent factor for research on social influence on CMC use. People from collectivistic cultures act in accordance with external expectations or social norms. The needs of in-groups supersede individual aspirations and their fulfillment [28]. Therefore, people are more likely to conform to group norms about how media are perceived and used. Group cohesion in collectivistic culture will have a greater influence on group member media perceptions and use than those in individualistic culture. The similarity in media perceptions and use is likely to be higher in collectivistic culture than in individualistic culture. Given that groups from some cultures may be more cohesive and prone to group conformity than groups in other cultures [44], culturally heterogeneous groups, namely groups composed of collectivistic and individualistic individuals, may be used to alleviate such problems. Accordingly,

Proposition 2a: Groups composed of collectivistic individuals will exhibit greater similarity in media perceptions than those composed of collectivistic and individualistic individuals, and groups composed of collectivistic and individualistic individuals will exhibit greater similarity in media perception than those composed of individualistic individuals.

Proposition 2b: Groups composed of collectivistic individuals will exhibit greater similarity in media use than those composed of collectivistic and individualistic individuals, and groups composed of collectivistic and individualistic individuals will exhibit greater similarity in media use than those composed of individualistic individuals.

\subsection{The Impact of Similarity of Media Perception and Use on Group Performance}

Fulk et al. [15] argue that the study of the consequence of media use could have an additional benefit of helping to answer the question of why study media choice. This paper goes beyond the prior studies and examines the impact of the similarity of media perception and use on group performance.

Groups exert pressure on individuals to conform to central attitudes and behaviors with norms acting as a mechanism to produce a homogeneity of values [39]. The higher the pressure for conformity, the greater the consistency of attitudes and behaviors, and the higher the satisfaction with job outcomes [31]. Postmes et al [34] demonstrated that conformity pressure found in groups is a mechanisms that, in most situations, regulates group interactions productively and which facilitates group performance. Group research in other contexts has shown that social interaction has important functions for member support and hence for the longer-range success of the group [29]. Based on Festinger's social comparison theory [12], Paulus and Dzindolet [32] found that group members tend to compare with others to reduce uncertainty about their abilities and opinions. They were motivated to match their performance with that of others and such matching process stimulated groups to reach fairly high levels of performance.

Consensus forms the basis of normative regulation of behavior and thereby sets the standard of, and expectations for, group members' behavior [34]. Thus, it seems reasonable to expect that groups that emerge with highly similar perceptions and use of communication media will be more productive than groups with less similar perceptions and media use.

\section{Proposition 3a: A higher degree of group similarity in media perception will improve group performance.}

Proposition 3b: A higher degree of group similarity in media use e will improve group performance.

\subsection{Social Construction Changes Over Time}

Social construction, almost by definition, is a dynamic reciprocal process occurring over time in which users continue to adapt their conventions to their (social) practice [7]. By interacting with others and observing them, over time, group members develop social norms about what they should be using the information technology for, how they should perceive it, and what is the appropriate manner of using it. The work group is an especially important source of social norms because interaction within the group was frequent and because group members were credible and powerful source of influence [26]. Postmes et al [35] have demonstrated that group 
norms will emerge over time such that interactions within the group will conform more and more to that which is typical of the group's style and content of interaction.

The emergence of norms should result in convergence over time. One-shot groups do not have an expectation for future meetings, which can negatively affect the social dynamics of a group [46]. Adaptive Structuration Theory (AST) posits that groups redefine their idiosyncratic uses of technology and that this is subject to perpetual change [7]. Walther [47] has emphasized the importance of temporal changes in social influence process in mediated interaction. His Social Information Processing (SIP) theory asserts that some amount of social information must be processed in order to form personal impressions and develop interpersonal relations. He concludes that the importance for relational development is not the amount of information processed in a single exchange, but the accrual and processing of information over a series of exchanges. Thus, to tap the processual aspects, it is necessary to study and measure group social influence, interaction, and outcomes over time to reveal the true nature of the relationships between these constructs.

Group cohesion is an outcome of the group development process. Thus, groups with a past history of working together can form different levels of cohesion among members over time [52]. A recent study demonstrated that conformity to group norms increase over time [35]. The important consideration here is that both the social construction and group performance are procedural in nature and subject to change over time [36]. Thus,

Proposition 4: Over time, group cohesion, similarity of media perception, similarity of media use, and group performance will be positively correlated.

\section{Implications and Conclusion}

This paper has addressed the issues of normative social influence on media perception and use, and group performance in different cultural group compositions. Previous research has established that social influence within a group is associated with various group-level outcomes when information technology has been employed, but relatively little was known about specific processes that accomplish this. Put another way, this paper attempts to add one answer to the question, "what intervening behaviors or processes are the mechanisms that allow groups with certain group characteristic profiles to create good outcomes?" The research model present in this paper suggests that we can extend the social influence model of technology use by identifying the impact of normative social influence on group members' media attitudes and use and group performance to understand why some groups succeed to a greater extent than others. At the same time, this paper advances a theory that takes culture into consideration by comparing culturally homogeneous and diverse groups. This will then allow for the examination of the impact of culture and cultural diversity on this extended model.

This research focuses on the interactions of group members from various national cultures as they communicate with each other to achieve group goals. Its purpose is served by a longitudinal field study. There are at least three advantages of such design over extant small group CMC research.

First, it has been argued that the use of ad hoc groups created specifically for laboratory experiments - common in much group research - can bias research findings with respect to the relationship of system use and outcomes. This suggests that the use of real groups faced with familiar tasks would be critical in obtaining results that may generalize to typical work settings. Second, most experiments are further limited in that the groups are temporary, completely ignoring the effects of time and history on group social interaction and outcomes. It has been argued that group work in organisations typically occurs over time and requires sustained interaction (Burke et al. 1999). The results of a group effort in an initial meeting are not necessarily indicative of the results realized in later meetings. Thus, it is necessary to study group social interaction and outcomes over multiple time periods to reveal the true nature or the relationships between these constructs. Third, most research on the effects of CMC use has been performed in controlled settings, and many use the method of comparing results when groups meet with and without the technology. This feature has deviated from actual work conditions, where information technology is used as a supplement to, rather than a substitute for, other modes of interaction. Straus (1997) found that interacting by CMC alone is inappropriate for both the instrumental and expressive functions of small groups, particularly when performing tasks that require consensus.

This study goes beyond prior research by incorporating all of these concerns into research design. In brief, matching longitudinal field studies could be conducted in the natural settings where teams exist naturally and independent of the research project, where teams have a similar semester-long 
project, and no constraints for communication media in three different cultural group compositions, as shown in Table 1. Table 1 also shows subject sources and the number of groups and subjects (in parentheses) in each cultural composition. Over twelve weeks, students will work as a group to perform a group assignment, a meaning task. They are required to provide their perceptions about the media and group behavior in week one, six and twelve. The aim of this study is to extend the Social Influence Model of Technology Use by evaluating the impact of normative social influence, incorporating the key moderator factor of national culture, on enhancing group performance through changing group members' media perceptions and use over time.

Table 1: Cultural Group Composition

\begin{tabular}{|l|l|l|}
\hline $\begin{array}{l}\text { Cultural } \\
\text { Composition }\end{array}$ & Subjects Source & $\begin{array}{l}\text { Group } \\
\text { Size }\end{array}$ \\
\hline $\begin{array}{l}\text { Culturally } \\
\text { homogeneous in } \\
\text { individualism }\end{array}$ & $\begin{array}{l}\text { Local university } \\
\text { students in Australian }\end{array}$ & $20(100)$ \\
\hline $\begin{array}{l}\text { Culturally } \\
\text { homogeneous in } \\
\text { collectivism }\end{array}$ & $\begin{array}{l}\text { Local university } \\
\text { students in China }\end{array}$ & $20(100)$ \\
\hline $\begin{array}{l}\text { Culturally } \\
\text { heterogeneous } \\
\text { including both } \\
\text { individualistic } \\
\text { and collectivistic }\end{array}$ & $\begin{array}{l}\text { International and } \\
\text { local university } \\
\text { students in New } \\
\text { Zealand and } \\
\text { Australia }\end{array}$ & $20(100)$ \\
\hline
\end{tabular}

The recognition that media perception and use occurs within a web of social relationships has important implications for both IS researchers and organizational managers. From the propositions, we assume that, in addition to considering informational social influence, researchers need to investigate the effect of normative social influence on media use within organizational groups that would influence

\section{References}

1. Anson, R., R. Bostrom, and B. Wynne, An experiment assessing group support system and facilitator effects on meeting outcomes. Management Science, 1995. 41(2): p. 189-208.

2. Baltes, B.B., et al., Computer-mediated communication and group decision making: $A$ meta-analysis. Organizational Behavior and group decision making performance. In other words, there is a need to expand the current theories of the social influence model of technology use to systematically investigate the joint effects of informational social influence and normative social influence. Further, this paper suggests that the strength of normative social influence on media use and group performance appears to vary when group composition varies by culture since theories applied in one culture do not necessarily apply in another. Researchers must consider cultural impact when applying theories in different cultural contexts.

From an organizational perspective, this paper suggests a way to align communication uses to the strategy of the organizations. By applying organizational norms, organizations can make a priori different interests between departments and individuals into consistent behavior. It also provides a preliminary guideline on how to develop effective organizational culture to encourage the use of new technologies, which in turn may affect employees' perceptions of the new technologies and organizational performance. Organizational culture can be an important source of social influence. This echoes the recent findings of Guo [20] that the impact of organizational culture greatly influences email use. But on the other hand, given that national culture influences human behavior and culturally diverse groups are fast becoming the norm in most large organizations, it is crucial for organizational managers to recognize such difficulties. Identifying these effects would be a vital first step toward establishing truly multicultural organizations in which the positive aspects of many cultures are accepted and incorporated and the value in diversity is recognized. Within today's global market environment, understanding cultural influence on employees' behavior will provide managers with a guideline for effectively improving organizational performance. Organizations that take into account their cultural diversity perform better [49].

Human Decision Processes, 2002. 87(1): p. 156179.

3. Bond, M.H. and K.C.W. Leung, How does cultural collectivism operate? The impact of task and maintenance contributions on reward distribution. Journal of Cross-Cultural Psychology, 1982. 13(2): p. 186-200.

4. Burke, K. and L. Chidambaram, How much bandwidth is enough? A longitudinal examination of media characteristics and group outcomes. MIS Quarterly, 1999. 23(4): p. 557-580. 
5. Chidambaram, L., Relational development in computer-supported groups. MIS Quarterly, 1996. 20(2): p. 143-165.

6. Cox, T., H. Lobel, and P. McLeod, Effects of ethnic group cultural differences on cooperative and competitive behavior on a group task. Academy of Management Journal, 1991. 34(4): p. 827-847.

7. DeSanctis, G. and M.S. Poole, Capturing the complexity in advanced technology use: Adaptive structuration theory. Organization Science, 1994. 5(2): p. 121-147.

8. Deutsch, M. and H.B. Gerard, A Study of normative and informative social influence upon individual judgment. Journal of Abnormal and Social Psychology, 1955. 51: p. 629-636.

9. Earley, P.C., Self or group? Cultural effects of training on self-efficacy and performance. Administrative Science Quarterly, 1994. 39(1): p. 89-117.

10. Erez, M. and P. Earley, Culture, Self-Identity and Work. 1993, Oxford: Oxford University Press.

11. Festinger, L., Informal social communication. Psychological Review, 1950. 57: p. 271-282.

12. Festinger, L., A theory of social comparison processes. Human Relations, 1954. 7: p. 117-140.

13. Festinger, L., H. Gerard, and B. Hymonitch, The Influence processes in the presence of extreme deviants. Human Relations, 1952. 5: p. 327-346.

14. Fulk, J., Social construction of communication technology. Academy of Management Journal, 1993. 36(5): p. 921-950.

15. Fulk, J. and B. Boyd, Emerging theories of communication in organizations. Journal of Management, 1991. 17(2): p. 407-446.

16. Fulk, J., J. Schmitz, and C.W. Steinfield, A Social influence model of technology use, in Organizational and Communication Technology, J. Fulk and C. Steinfield, Editors. 1990, Sage Publications: Newbury Park, CA. p. 117-142.

17. Fulk, J., et al., A Social information processing model of media use in organizations. Communication Research, 1987. 14(5): p. 529552.

18. Gudykunst, W.B., Y. Matsumoto, and S. TingToomey, The influence of cultural individualismcollectivism, self construals, and individual values on communication styles across cultures. Human Communication Research, 1996. 22(4): p. 510543.

19. Gully, S.M., D.J. Devine, and D.J. Whitney, $A$ meta-analysis of cohesion and performance: Effects of level of analysis and task interdependence. Small Group Behavior, 1995. 26(4): p. 497-520.

20. Guo, Z., Cultural Influence on Communication Media Choice Behavior: A Cross-Cultural Study within Multinational Organizational Settings, in Information Systems. 2002, University of New South Wales: Sydney.

21. Guo, Z., J. D'Ambra, and B. Edmundson. Understanding culture influence on media choice behavior: A cross-cultural study within multinational organization setting. in Proceedings of Thirteen Pacific Asia Conference on Information Systems. 2001. KOREA.

22. Hofstede, G., Culture's Consequence: International Differences in Work-Related Values. 1980, Beverly Hill, CA: Sage Publications.

23. Hofstede, G., Culture's Consequences: Comparing Values, Behaviors, Institutions, and Organizations Across Nations. 2nd ed. 2001, Thousand Oaks, CA: Sage.

24. Hogg, M.A., The Social Psychology of Group Cohesiveness: From Attraction to Social Identity. 1992, New York: New York University Press.

25. Kaplan, M.F. and C.E. Miller, Group decision making and normative versus informational influence: Effects of types of issue and assigned decision rule. Journal of Personality and Social Psychology, 1987. 53(2): p. 306-313.

26. Kraut, R.E., et al., Varieties of social influence: The role of utility and norms in the success of a new communication medium. Organization Science, 1998. 9(4): p. 437-453.

27. Lee, E.-J. and C. Nass, Experimental tests of normative group influence and representation effects in computer-mediated communication: When interacting via computers differs from interacting with computers. Human Communication Research, 2002. 28(3): p. 349381.

28. Martinsons, M.G. and R.I. Westwood, Management information systems in the Chinese business culture: An explanatory theory. Information \& Management, 1997. 32(5): p. 215 228.

29. McGrath, J.E., Time, interaction and performance(TIP): A theory of groups. Small Group Research, 1991. 22(2): p. 147-174.

30. Moscovici, S., Social Influence and Social Change. 1976, London; New York: Academy Press.

31. O'Reilly III, C.A. and D.F. Caldwell, The Impact of normative social influence and cohesiveness on task perceptions and attitudes: A social 
information processing approach. Journal of Occupational Psychology, 1985. 58: p. 193-206.

32. Paulus, P.B. and M.T. Dzindolet, Social influence process in group brainstorming. Journal of Personality and Social Psychology, 1993. 64(4): p. 575-586.

33. Pfeffer, J., Organizations and Organization Theory. 1982, Marshfield, MA: Pitman.

34. Postmes, T. and M. Lea, Social process and group decision making: Anonymity in group decision support systems. Ergonomics, 2000. 43(8): p. 1252-1274.

35. Postmes, T., R. Spears, and M. Lea, The formation of group norms in computer-mediated communication. Human Communication Research, 2000. 26(3): p. 341-371.

36. Reinig, B.A. and B. Shin, The dynamic effects of group support systems on group meetings. Journal of Management Information Systems, 2002. 19(2): p. 303-325.

37. Rice, R.E., J. D'Ambra, and E. More, Crosscultural comparison of organizational media evaluation and choice. Journal of Communication, 1998. 48(3): p. 3-26.

38. Salancik, G.R. and J. Pfeffer, A Social information processing approach to job attitudes and task design. Administrative Science Quarterly, 1978. 23: p. 224-253.

39. Santee, R.T. and J. Jackson, Cultural values as a source of normative sanctions. Pacific Sociological Review, 1977. 20: p. 439-454.

40. Schmitz, J. and J. Fulk, Organizational colleagues, media richness and electronic mail: A test of the social influence model of technology use. Communication Research, 1991. 18(4): p. 487-523.

41. Singelis, T.M. and W.J. Brown, Culture, self, and collectivist communication: Linking culture to individual behavior. Human Communication Research, 1995. 21(3): p. 354-389.

42. Smith, P.B., S. Dugan, and F. Trompenaars, National culture and the values of organizational employees: A dimensional analysis across 43 nations. Journal of Cross-Cultural Psychology, 1996. 27(2): p. 231-264.

43. Straus, S.G. "Technology, group, process, and group outcomes: Testing the connections in computer-mediated and face-to-face groups," Human-Computer Interaction (12:3) 1997, pp 227-266.

44. Tan, B., R. Watson, and K.K. Wei, National culture and group support systems: Filtering communication to dampen power differentials.
European Journal of Information Systems, 1995. 4(2): p. 82-92.

45. Tan, B.C.Y., et al., Computer-mediated communication and majority influence: Assessing the impact in an individualistic and a collectivistic culture. Management Science, 1998a. 44(9): p. 1263-1278.

46. Triandis, H.C., Individualism and Collectivism. 1995a, Boulder, Colo.: Westview Press.

47. Walther, J.B., Group and interpersonal effects in international computer-mediated collaboration. Human Communication Research, 1997. 23(3): p. 342-369.

48. Walther, J.B. and J.K. Burgoon, Relational communication in computer-mediated interaction. Human Communication Research, 1992. 19(1): p. 50-88.

49. Watson, R.T., T.H. Ho, and K.S. Raman, A fourth dimension of group support systems.

Communications of The ACM, 1994. 37(10): p. 45-55.

50. Watson, W., K. Kumar, and L. Michaelson, Cultural diversity's impact on interaction process and performance: comparing homogeneous and diverse task groups. Academy of Management Journal, 1993. 36(3): p. 590-602.

51. Webster, J. and L.K. Trevino, Rational and social theories as complementary explanations of communication media choices: Two policycapturing studies. Academy of Management Journal, 1995. 38(6): p. 1544-1572.

52. Wheeler, L., H.T. Reis, and M.H. Bond, Collectivism-individualism in everyday social life: The Middle Kingdom and the melting pot. Journal of Personality and Social Psychology, 1989. 57(1): p. 79-86.

53. Yoo, Y. and M. Alavi, Media and group cohesion: Relative influences on social presence, task participation, and group consensus. MIS Quarterly, 2001.25(3): p. 371-390.

\section{Acknowledgement}

This project is currently funded by The University Of New South Wales through a Faculty Research Program Grant (2005). 